index comunicación | no 12(1) 2022 | Páginas 13-19

E-ISSN: 2174-1859 | ISSN: 2444-3239 | Depósito Legal: M-19965-2015

Recibido el 28_11_2021 | Aceptado el 02_12_2021 | Publicado el 15_01_2022

\title{
POLÍTICA POP ONLINE: NUEVAS ESTRATEGIAS Y LIDERAZGOS PARA NUEVOS PÚBLICOS
}

\section{Pop Online Politics: New Strategies and Leaderships for New Audiences}

https://doi.org/10.33732/ixc/12/01Politi

Salomé Berrocal-Gonzalo Universidad de Valladolid salome.berrocal@uva.es

https://orcid.org/0000-0002-0483-0509

\section{Raquel Quevedo-Redondo}

Universidad de Valladolid raquel.quevedo.redondo@uva.es https://orcid.org/0000-0002-6219-3237

\section{Virginia García-Beaudoux} Universidad de Belgrano y Universidad de Buenos Aires dagar02@gmail.com https://orcid.org/0000-0003-2428-8056

Proyecto «Politainment ante la fragmentación mediática: desintermediación, engagement y polarización» (Ref. PID2020-114193RB-I00), concedido por el Ministerio de Economía y Competitividad 
14

Resumen: En la sociedad del entretenimiento, generada a finales del siglo XX, se desarrolla la política pop, una fórmula de comunicación utilizada por los líderes políticos para hacer llegar su imagen y mensaje a la ciudadanía utilizando ingredientes del espectáculo o de celebritización. En un sentido parecido actúan los medios de comunicación tradicionales, que incluyen formatos de infoentretenimiento político, para trasladar la información política a los ciudadanos en un formato frívolo, superficial o satírico, con el fin de ganar audiencia. Esta situación de dominio del politainment se ha transferido a Internet, donde el fenómeno multiplica su expansión a través de las redes sociales. Allí, partidos políticos, medios de comunicación y prosumidores encuentran un espacio para captar el voto, ganar audiencia u obtener algún beneficio. El monográfico incluido en index.comunicación presenta investigaciones en politainment, con el objeto de examinar su presencia en medios convencionales y en redes sociales. Las nuevas fórmulas que adopta la información política espectacularizada, el tipo de emisores que la producen y las consecuencias entre quienes la consumen son objeto de análisis en los trabajos publicados en este número temático.

Palabras clave: política-pop; politainment; celebritización; comunicación política; redes sociales; infoentretenimiento.

Abstract: In the midst of entertainment society, that started off at the end of the twentieth century, pop politics developed as a new communication formula used by the political leaders to share their image and their messages to the citizens by means of features from the entertainment environment or celebritization. In a similar way, the traditional mass media act, including formats of political infoentertainment to share the political information to the citizens in a frivolous, superficial or satiric format, aiming to increase their audience. This dominant situation of politainment has been transferred to the Internet environment, where the trend multiplies its effect due to the power of social networks. In that case, political parties, mass media and prosumers, find a new space to gain votes, increase their audience and achieve advantage. The monograph included in index.comunicación introduces several research projects related to politainment, aiming to study its impact upon traditional media and social networks. The new formulas adopted by spectacularized political information, the kind of issuers that produce them and the consequences upon those who intake them, are the object of analysis of the investigation works published in this thematic number.

Keywords: Politics-pop; Politainment; Celebritization; Political Communication; Social Networks; Infotainment. 


\section{Introducción}

En la era de lo que Mazzoleni y Sfardini denominan «política pop» (2009), el espectáculo ha invadido un territorio reservado durante décadas al ámbito puramente informativo, convirtiendo los detalles sobre la privacidad y personalidad de los gobernantes en objeto de las pretensiones de conocimiento que imperan en la sección, a menudo veleidosa, alimentada por las celebridades.

En 1997, David Marshall reflexionaba en una de sus más reconocidas obras sobre el peculiar nexo de unión entre el concepto de «celebridad» y los rasgos característicos del poder, con el fin de profundizar en el innato deseo del ser humano por descubrir en los personajes públicos un reflejo de sus propias inquietudes, rutinas y anhelos. En este contexto, la Enciclopedia Internacional de la Comunicación Política recoge el término «celebrity politics» (Richardson, 2015) para aludir al recodo de la investigación en ciencias sociales que atiende a la manera en que rostros conocidos del panorama internacional (políticos o no), combaten la apatía del elector con acciones que permiten humanizar a las figuras gubernamentales y contribuir a la propagación de un mensaje digerible y ameno.

La proliferación de contenidos sobre información política espectacularizada o politainment se ha incrementado con el creciente uso de redes sociales como Facebook, Twitter o Instagram, donde los públicos menos interesados en la actualidad parlamentaria pueden encontrar imitaciones hilarantes, memes y vídeos de talk shows relacionados con la esfera gubernamental. A este respecto y siguiendo la vía que marcan los recientes estudios sobre «política pop online» (Bracciale y Mazzoleni, 2019), el presente monográfico reúne propuestas que ahondan en estrategias de captación del voto enfocadas a públicos diversos, nuevos tipos de liderazgo y celebritización del poder en redes sociales, entre otros fenómenos que evolucionan al calor de la cultura popular.

El politaiment televisivo se aprecia desde los años 90 del siglo XX a través de la presencia de los políticos en distintos formatos de televisión: informativos, programas contenedores o talk shows. Programas en los que se tiene en cuenta no solo el enfoque temático sino también el estilístico, de forma que no solo implica una elección noticiosa sino también un tratamiento de esa información caracterizado por un dominio de mensajes simples, emotivos y sensacionalistas y que cuenta, en ocasiones, con la propia colaboración de los protagonistas noticiosos (Labio Bernal, 2008).

En el desarrollo y expansión del fenómeno inciden novedades comunicativas que se han producido en los últimos treinta años, como la proliferación de los canales informativos de 24 horas, la expansión de Internet con sus nuevos formatos de noticias y la alta competencia audiovisual, circunstancias que 
contribuyen a que el infoentretenimiento se haya convertido en una fórmula para comunicar de máxima relevancia. Neijens (1998) defiende que el incremento de canales y nuevas fuentes de información que se han desarrollado desde los años 90 ha contribuido al desarrollo del infoentretenimiento. Moy et al. indican que el incremento del infoentretenimiento se debe a las necesidades de los programas de televisión en combatir sus bajas audiencias (Moy, Xenos \& Hess, 2005). Kovach y Rosentiel (2007) añaden que contribuye a la expansión del politainment su rentabilidad económica, al defender que es más barato producir este tipo de contenidos en televisión. Resulta más económico producir un talk show que incluya posiciones encontradas de periodistas y políticos sobre un determinado tema que un reportaje periodístico de investigación en formato tradicional, en el que se necesite invertir en el desplazamiento de un equipo de reporteros a una determinada zona y tiempo de trabajo para poder elaborar un reportaje en profundidad. Atkinson (2011) afirma que el «Mcjournalism» es el camino más rápido para producir un producto más barato y conseguir más publicidad.

Los políticos optan por este tipo de programas con el deseo de encontrar un nuevo público que no consume informativos y que es parte del electorado. Los líderes políticos consideran que estos espacios son una posibilidad para darse a conocer en su faceta más personal y, en ocasiones, la simpatía que muestran, la anécdota que cuentan, el simple hecho de dar a conocer su historia personal puede contribuir en lograr un acercamiento de parte del electorado. Así, con el título El espectáculo de la política en El Hormiguero 3.0 con los candidatos a la presidencia del Gobierno: 2015-2019, se presenta un trabajo que muestra cómo los candidatos recorren los platós de televisión durante la campaña electoral mostrando sus dotes comunicativas. El artículo analiza los programas que se emitieron durante las campañas electorales celebradas entre 2015 y 2019, examinando tanto el contenido como la estructura, fijándose de manera particular en el tratamiento que recibieron los distintos líderes políticos a lo largo del programa con el objeto de evaluar si existió la imparcialidad necesaria o se produjo un sesgo positivo o negativo hacia alguno de ellos.

Siguiendo con la línea investigadora imbricada en el ámbito del infoentretenimiento político televisivo, se sitúa la investigación La Unión Europea bajo el prisma de la política pop. La serie Parlement (2020), entre la ficción y el realismo. Un estudio que se centra en el análisis de la única serie de ficción que versa sobre el funcionamiento de la Unión Europea: la producción francobelga-alemana Parlement. Un trabajo que pone de manifiesto cómo Parlement trabaja con estereotipos y percepciones sociales sobre la Unión Europea des- 
de la sátira, pero, al mismo tiempo, ofrece elementos pedagógicos en todos sus episodios. Un trabajo que viene a sumarse a la doble visión existente en torno al politainment entre aquellos que defienden cómo este tipo de formatos contribuyen a la simplificación y conversión de la política en un espectáculo y aquellos que opinan que de esta manera los ciudadanos se sienten más próximos al político y a la institución que representa.

En la sociedad digital, políticos, medios de comunicación y ciudadanos convergen en el uso de las redes sociales, un lugar donde establecer una nueva comunicación. La reducción de la política a historias seductoras de sus personajes, la explotación propagandística de las emociones, la difusión de escándalos políticos y la proliferación de anécdotas banales correspondientes a la política espectáculo continúan dominando el paisaje virtual (Dader, 2012) de la misma manera que estas fórmulas habían colonizado ya la prensa y el medio audiovisual.

La expansión del fenómeno alcanza a las redes sociales, lugar donde los políticos, medios de comunicación y receptores convertidos en prosumidores tratan de utilizarlas como altavoces para enviar mensajes o provocar conversaciones con los consumidores. En estas conversaciones, la audiencia no solo consume, sino que responde y reproduce mensajes y crea otros casi simultáneos. La viralidad del politainment es muy importante en Internet.

En esta línea de trabajo, la política espectacularizada en la Red, se ubica el artículo Estrategia programática en Instagram de los candidatos en las Elecciones Autonómicas de la Comunidad de Madrid 2021, que muestra el uso de la red social Instagram como herramienta para la difusión de las líneas programáticas de partido, así como de la imagen del candidato, en las elecciones a la Comunidad de Madrid en 2021. El estudio analiza el contenido de los tuits, el protagonismo del líder y su argumentación propagandística en el caso de los seis principales aspirantes a la presidencia autonómica, al mismo tiempo que trata de medir las posibles estrategias de celebrificación del líder.

A este campo investigador también se suma el artículo Narrativa de campaña en Instagram: espectáculo y autorepresentación de candidatos. El caso de las elecciones generales 2019, al examinar las estrategias que usaron los partidos políticos en sus publicaciones en Instagram durante la campaña de las elecciones del 10 de noviembre de 2019, en términos de su contenido y recursos mediáticos, en el entorno de política-espectáculo. Los resultados indican una brecha entre los partidos de nueva y vieja política en el uso de Instagram, mientras que el recurso a la personalización varía entre formaciones.

Además de Instagram, la red social Twitter es empleada por políticos y medios para llegar hasta los ciudadanos. Un ejemplo de ello es la participación 
de los programas de politainment en Twitter, con el objeto de ganar audiencia social y obtener una mayor repercusión mediática. El trabajo titulado Estudio de la audiencia social en Twitter de los formatos de politainment en España. El caso de El Intermedio profundiza en los programas televisivos de infoentretenimiento político emitidos en 2018 en España y analiza de manera particular el comportamiento del infoshow El Intermedio, así como el engagement de su audiencia social en Twitter.

Además, el monográfico incluye un estudio que propone el concepto de tecnopolítica como una vía para reflexionar acerca de los cambios mediáticos que se están produciendo. Con el título: Repensando la tecnopolítica desde los procesos electorales 2012 y 2018 en México se concluye que este término se puede definir como un proceso de ensamblaje donde interactúan actores, con objetivos políticos diferenciados, que buscan transformar una historicidad dada o aspiran a conservar las estructuras políticas existentes, a través de movilizaciones, acciones en redes sociodigitales, creación de contenidos audiovisuales y otras apropiaciones tecnológicas.

La política espectacularizada se extiende en el panorama mediático actual como manifiesta este monográfico a través de los distintos trabajos presentados. Al mismo tiempo, esta publicación evidencia una línea de investigación sólida, que surge en España en el año 2000, en la que se siguen planteando nuevos interrogantes que tienen que ver con los efectos en la opinión pública de una información frívola, superficial o satirizada ante los que no hay una respuesta definitiva. El nacimiento de nuevos formatos y medios procura interés al campo científico y añade temáticas diferenciadas en las que se hace necesario seguir indagando y que tienen que ver con el uso que realizan los emisores, el consumo y participación que llevan a cabo los consumidores/prosumidores y las fórmulas que adopta el politainment atendiendo al soporte utilizado para su difusión.

\section{Referencias bibliográficas}

ATKINSON, J. (2011). Performance journalism: a three-template model of television news. The International Journal of Press/Politics, 16(1).

\section{doi.org/10.1177/1940161210381646}

DADER, J.L. (2012). Periodismo político y política del periodismo: Imaginando un futuro digno y sostenible. En BERROCAL, S. y CAMPOS, E., La investigación en periodismo político en el entorno de los nuevos medios. Sociedad española de Periodística.

KOVACH, B. \& ROSENTIEL, T. (2007). The elements of journalism: what newspepople should know and the public should expect to know. Three Rivers. 
LABIO BERNAL, A. (2008). Periodismo de entretenimiento: la trivialización de la prensa de referencia. Estudios sobre el Mensaje Periodístico, 14.

MARSHALL, P.D. (1997). Celebrity and power: fame in contemporary culture. University of Minnesota Press.

MAZZOLENI, G. \& BRACCIALE, R. (2019). La politica pop online. I meme e le sfide della comunicazione politica. Il Mulino.

Mazzoleni, G. \& Sfardini, A. (2009). Politica pop. Da 'Porta Porta' a 'L'ísola dei famosi. Il Mulino.

MoY, P., XeNOS, M.A. \& Hess, V.K. (2006). Priming effects of late-night comedy. International Journal of Public Opinion Research, 18. doi.org/10.1093/ijpor/edh092

NeIJENS, P. \& BRANTS, K. (1998). The infotainment of politics. Political Communication, 15(2).

RICHARDSON, K. (2015). Celebrity politics, The International Encyclopedia of Political Communication. Wiley Online Library. 